\title{
El pasAdo COMO PROBlema ANTROPOLÓgico
}

\author{
SANTIAGO MORA \\ St. Thomas University (NB, Canadé) \\ MORA@sTu.cA
}

Resumen

[STE ARTí́CULO TRATA EL PROBLEMA DEL PASADO DESDE LA PERSPECTIVA DE ETNÓGRAFOS-ETNÓLOGOS E(antropólogos) y arqueólogos. Es un intento por entender cómo los modelos producidos por los antropólogos tienen un impacto sobre el trabajo de los arqueólogos y cómo el trabajo de estos últimos afecta la visión que del pasado tienen los primeros. Aunque el texto se refiere de manera general en la antropología, enfoca esta problemática en el desarrollo de la antropología en Colombia. Examina el uso de las analogías etnográficas que relacionan el pasado con el presente dada su importancia para la ilustración del pasado colombiano.

PALABRAS CLAVE: antropología, etnografía, arqueología, analogía etnográfica, Colombia.

\section{THE PAST AS ANTHROPOLOGICAL PROBLEM}

\begin{abstract}
THIS ARTICLE CONSIDERS ETHNOGRAPHERS-ETHNOLOGISTS (ANTHROPOLOGISTS) AND ARCHAEOLOGISTS perspectives of the past. It is an attempt to understand how the models produced by anthropologists impact archaeologists' work and how the latter influence anthropologists' views of the past. Although the text refers to general anthropology, it focuses on the development of Colombian anthropology. The use of ethnographic analogies that link past and present due to its importance in the illustration of the Colombian past are examined.
\end{abstract}

KEY wORDs: Anthropology, ethnography, archaeology, ethnographic analogy, Colombia.

\section{Revista Colombiana de Antropología}

Volumen 43, enero-diciembre 2007, pp. I57-I96 
N O EXISTE El PASADO, ABSURdo NEGARLO ${ }^{1}$. IMPOSIBLE VIVIR EN UN presente sin pasado. Esta disyuntiva encierra un importante problema antropológico, responsable de la estructura académica de muchos departamentos de antropología en el nuevo mundo. Indudablemente, desde la época de Franz Boas surgieron el experto en el presente, el etnógrafo y el arqueólogo especialista en el pasado. A pesar de esta barrera generada por las especialidades, los resultados de unos y otros se esperaba fueran complementarios; después de todo, es innegable que la historia, inclusive aquella de las comunidades no occidentales, es parte de un continuo que se extiende desde tiempos remotos para llegar al presente del cual son testigos los etnógrafos y desde el que escribimos sobre el pasado.

Esta separación temporal en las especialidades creó múltiples divergencias. Unas de las más destacadas se verificaron en el campo metodológico. Los arqueólogos y particularmente aquellos de los inicios de la disciplina, condenados a ver el mundo a través de algunos pocos restos de la cultura material, centraron sus esfuerzos en clasificar cuidadosamente todos los artefactos, de cierta antigüedad, que podían encontrar. Las tipologías surgidas de esta forma intentaban organizar los eventos humanos en secuencias temporales dentro de conjuntos demarcados por un sello que permitía reconocer una "identidad", a la cual, en un principio, se llamó Cultura. Un problema que resultó evidente desde entonces era la validez temporal de estas identidades. Hacia mediados

I. Este artículo fue posible gracias al apoyo proporcionado por una beca de investigación de St. Thomas University. Los comentarios de Carlos Franky y Franz Flórez, así como los realizados por los lectores anónimos de este texto contribuyeron a mejorar su calidad y estimularon su proceso de corrección. Los errores, simplificaciones y omisiones siguen siendo míos.

2. Véase, por ejemplo, el debate entre Spaulding (I953; I954) y Ford (I954a, I954b) y O'Brien y Lyman (2002). Para autores como Rouse (I960) esta cuestión sólo se podría aclarar con una aproximación directa, es decir a partir de la opinión de quienes participaban en esta cultura. Un problema semejante intenta abordar la antropología, guardadas las diferencias, con los conceptos de émico y ético.

caban. En breve, se debatía la capacidad de las clasificaciones hechas por los arqueólogos para revelar una "realidad pasada del siglo pasado esta dificultad generó preguntas como las siguientes: ¿habían reconocido los nativos del pasado las fronteras culturales que los arqueólogos identificaban? ¿Hasta dónde las clasificaciones de los arqueólogos se aproximaban a las que organizaban el mundo de los nativos? ${ }^{2}$. No menos importantes eran los problemas inherentes a la definición de las variables que debían incluir estos tipos, y los contextos en los que se apli- 
significativa” y por tanto acorde con los diferentes estudios que se realizaban. Obviamente, estos problemas generaron y siguen generando controversias. De tanto en tanto algunos regresan, con una nueva óptica, al mismo problema ${ }^{3}$. En esencia, las discusiones giran en torno de la siguiente pregunta: ¿cómo se deben organizar los datos para poder leer y constatar una realidad pasada que tenga sentido a través de los tiempos?

3. Posiblemente, el más reciente retorno a esta problemática, desde la perspectiva de la arqueología latinoamericana, sean los textos incluidos en el volumen Contra la tiranía tipológica en arqueología: una visión desde Suramérica, editado por Cristóbal Gnecco y Carl Henrik Langebaek (2006a).

Por su parte, los antropólogos, y particularmente los etnólogos, se consideraban a sí mismos como testigos presenciales de los eventos que estudiaban. Esto es cierto tanto para aquellos del nuevo mundo, como para los que habitaban al otro lado del Atlántico. El presente etnográfico es, por decirlo de alguna manera, un presente continuo. A pesar de que en Europa la arqueología no fue parte de la antropología, la identidad de los etnólogos de uno y otro lado del Atlántico les permitía diferenciarse claramente, desde el punto de vista de su trabajo como académicos, de historiadores y arqueólogos. Diferencia que permanece. El exótico otro se ha desvanecido y ha sido reemplazado por un "nosotros", el cual los antropólogos estudian en un presente inmediato. Dice Augé:

La antropología siempre ha sido una antropología del aquí y el ahora. El etnólogo en ejercicio es aquel que se encuentra en alguna parte (su aquí del momento) y que describe lo que observa o lo que oye en ese mismo momento (I996: 15-16).

La separación temporal entre antropólogos y arqueólogos alimentó otras diferencias y contribuyó a que sus estudios marcaran énfasis dispares. Los arqueólogos, de forma general, se habían inclinado un poco más hacia las ciencias naturales; la sentida necesidad de comprender los ámbitos extintos en los cuales los humanos actuaron los forzó a seguir esta ruta. Algunos de estos arqueólogos se transformaron en verdaderos expertos en campos como la paleobotánica, la zoología o la pedología. Esto fue particularmente cierto después de la revolución conocida como “nueva arqueología”, que impulsó la construcción de modelos que enfatizaban los componentes ambientales en los sistemas sociales. Estos diseños, en teoría, podían aplicarse a instrumentos 
individuales o a amplios conjuntos de sitios ${ }^{4}$. Por su parte los antropólogos orientaban sus esfuerzos en otras áreas. Algunos de ellos, de la mano de los nuevos desarrollos del pensamiento antropológico del siglo veinte, como el estructuralismo, profundizaron en aspectos de la lingüística y la semiótica, áreas por entonces remotas para la gran mayoría de arqueólogos.

Estas diferencias en sus formaciones y en sus aproximaciones a las sociedades no quieren decir que sus trabajos no pudieran converger. Por ejemplo, cuando surgió y se consolidó, a partir de la década de 1950, una profunda inquietud por la ecología, rápidamente ambos grupos de antropólogos pudieron responder adecuadamente con ideas y programas de investigación que resaltaban estas temáticas. Son testimonio de lo anterior las etnografías que desde entonces se realizaron en diferentes regiones de Sudamérica, y particularmente en la amazonia ${ }^{5}$. Inclusive importantes teóricos como Claude Lévi-Strauss (1985), que se habían concentrado en otros aspectos de las sociedades humanas, se ocuparon del asunto ${ }^{6}$. Desde entonces, los problemas ambientales y la percepción misma del entorno han sido un aspecto en el cual coinciden antropólogos y arqueólogos ${ }^{7}$.

A pesar de que son evidentes muchas de las diferencias y semejanzas entre antropólogos y arqueólogos, no son tan claras las

4. En este sentido se orientó la propuesta de Butzer (1982) para una arqueología contextual en la cual se empleaba una matriz de cuatro dimensiones para enmarcar los componentes ambientales y culturales.

5. Un claro ejemplo de esto es el trabajo de tesis doctoral de P. Descola, influenciado por importantes estructuralistas y marxistas de la época. Véase Descola (I987).

6. Véase el capítulo 7, "Structuralism and ecology": I2I-I37.

7. La producción de los antropólogos colombianos de los últimos veinte años señala claramente esta problemática como uno de los aspectos a los cuales se han dedicado más arduamente. Unos pocos ejemplos se encuentran en Correa (I990); Reichel-Dolmatoff (I977); Reichel (I989); Palacio y Ulloa (2002). ca. Espero señalar algunas dificultades implícitas en el uso de los supuestos generados por cada una de estas secciones de la antropología en general, y en particular para el caso colombiano. de especialistas han contribuido a la construcción de la visión temporal del otro. Esta es la materia de este escrito. Intento abordar la relación pasado-presente moviéndome en torno de las influencias que etnógrafos-etnólogos y arqueólogos ejercieron sobre su contraparte. Examino esta relación en un marco general construido desde algunas de las perspectivas generadas por una antropología de corte estadounidense, que ha tenido y tiene una gran influencia en Latinoaméri-

formas en que estos dos conjuntos

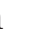

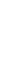


Indudablemente, se trata de un problema que se torna muy interesante ahora que los antropólogos, en general, retoman el problema de la historia y los arqueólogos se ven forzados por las nuevas tendencias teóricas a repensar los supuestos sobre los cuales basaron sus reconstrucciones.

Con el fin de abordar esta relación, señalo algunas de sus consecuencias en las miradas de antropólogos y arqueólogos y me concentro en el empleo de las analogías etnográficas. Por analogía entiendo el razonamiento que encuentra semejanzas entre cosas distintas, basado en la existencia de atributos o rasgos equiparables. La analogía etnográfica, entonces, reconoce semejanzas entre situaciones etnográficas y casos provenientes del estudio del registro arqueológico. El empleo de la analogía, desde el punto de vista de los arqueólogos, tiene por objeto establecer un "puente" entre el pasado y el presente. Hodder (I999: 46) discute tres formas en las que se formula este puente. En la primera de ellas las analogías etnográficas se toman como "sustancia" para explicar o completar la descripción de un determinado suceso del pasado. En segunda instancia las analogías son empleadas como fuentes para ampliar y desarrollar otras posibilidades de interpretación del registro arqueológico. Por último, se usan para poner a prueba algunas ideas que tenemos sobre el pasado. Aquí, de forma particular, exploro el uso de las analogías etnográficas como ilustraciones que dan vida al pasado. Veo este uso como un puente que es posible cruzar en dos direcciones: desde el presente hacia el pasado y desde el pasado hacia el presente. Por tanto, considero que la ilustración del pasado, a partir de la analogía etnográfica, al enseñar aspectos específicos del pasado, transforma la misma apreciación etnográfica al darle unas características temporales que no tenía antes. Incluyo en la argumentación el papel de la etnología, la etnografía y las contribuciones realizadas a partir del dato etnohistórico, así como la visión-representación que se elabora para el público en general y que se reproduce en el museo. Empleo algunos ejemplos provenientes del trabajo de los antropólogos y arqueólogos colombianos con el propósito de ubicar esta problemática en el contexto de la academia colombiana. Un problema será evidente: la arqueología y la etnología-etnografía del país han manejado las elaboraciones teóricas de forma poco explícita, fenómeno que contribuye a dificultar la verificación de las relaciones entre estas dos secciones. Después de todo, los referentes teóricos constituyen la articulación que justifica 
históricamente estas relaciones dentro de un corpus general que constituye la práctica académica de la antropología. También uso ejemplos de la amazonia. La selección de esta región para señalar estos puntos es muy sencilla: ha producido y produce un importante volumen de informaciones etnográficas. Estas informaciones han sido empleadas de forma corriente por los arqueólogos y antropólogos para ilustrar el pasado.

\section{El pASADO Y EL PRESENTE}

\section{Antropólogos}

LA HISTORIA DE LA ANTROPOLOGÍA EN EL CONTINENTE MUESTRA ACERCAmientos y distanciamientos en el trabajo de los antropólogos con respecto a los problemas históricos. Fundadores de la disciplina en las Américas, como Franz Boas, sintieron la necesidad de incorporar la historia como parte de aquello que debíamos saber sobre las sociedades que estudiaban. Para este investigador la mayor complejidad de los estudios antropológicos, en comparación con las ciencias naturales, radicaba en la necesidad de incluir todos y cada uno de los fenómenos, no sólo como efectos sino como causas (Boas, I996). Así, la historia cobró una importancia inusitada como el punto donde convergían causas y efectos-causa. Una larga cadena de relaciones se extendía desde y hacia el pasado. A pesar del interés de Boas por la historia, fue un destacado opositor de los modelos evolutivos propuestos por sus contemporáneos. Entre otras cosas porque para él no existían suficientes datos que comprobaran este tipo de construcciones (Carneiro, 2003; White, 1947, 1968).

Con el revivir del interés por la evolución a manos de los neo-evolucionistas, a mediados del siglo veinte, el pasado remoto cobró una posición verdaderamente destacada en antropología. Durante el periodo que antecedió la segunda gran guerra los antropólogos, especialmente en Estados Unidos, se encontraban más ocupados por el presente, presente que los dirigía a la confrontación. El énfasis marcado por autores como Steward (1977), White (1943, 1949), Service (I97I, I975) y Sahlins (I990) durante la posguerra contribuyó al desarrollo de una teoría antropológica del cambio cultural que comprendía la totalidad de la historia. Era 
posible edificar modelos para explicar el cambio cultural, como lo hiciera Fried (I967), dando cuenta de la totalidad de la historia de la humanidad. Así se hacía indispensable el conocimiento arqueológico para el saber antropológico; la arqueología había dejado de ser tan solo una sección periférica de la antropología, puesto que se encontraba en capacidad de hacer contribuciones teóricas al corpus general de la antropología (Lyman, 2007). Una consecuencia de lo anterior fue que las interacciones entre estas dos secciones de la antropología se multiplicaron; el pensamiento de algunos antropólogos pronto se reflejó en las construcciones que los arqueólogos realizaban. Un ejemplo claro se encuentra en Binford (1962), donde es palpable la influencia de L. White en la definición de los sustratos analíticos propuestos -ideo-técnico, socio-técnico y tecnómico- que semejan aquellos trazados por White (I949) con anterioridad.

En países como Colombia los modelos evolucionistas propuestos y empleados por los antropólogos estadounidenses no tuvieron una gran influencia, en general. Es posible que por ello en ese momento no se diera una asociación tan estrecha en el trabajo de arqueólogos y antropólogos; después de todo no tenían como objetivo común el contribuir, desde diferentes perspectivas, a una teoría general como lo es la evolución cultural. No obstante, en esa época Reichel-Dolmatoff (1965), quien edificó gran parte de la antropología y arqueología colombiana del siglo veinte, publicó su primera síntesis de la historia anterior a la conquista española basándose en un modelo evolucionista. A pesar de ello la producción de los demás antropólogos estaba centrada en otras temáticas; los arqueólogos, a partir de entonces, se ocuparon de "producir materiales" para alimentar las historias culturales o adicionar algunos datos al modelo propuesto por Reichel-Dolmatoff. Sin embargo, no hubo una discusión sobre las consecuencias teóricas y metodológicas de la adopción de estas ideas.

En la década de I980 el marco evolutivo había dejado de ser atractivo para la gran mayoría de los etnógrafos y etnólogos, aun cuando en algunos de ellos persistiera el interés por la historia. Esto llevó al abandono del estudio del lapso para el cual se había diseñado una compleja teoría evolutiva; simultáneamente, perdía terreno el trabajo de los etnólogos que intentaban involucrar las variables prescritas por los modelos evolucionistas. Antropólogos y arqueólogos tomaban rutas diferentes en cuanto a sus concepciones del tiempo y el tratamiento del mismo. A 
partir de entonces, el periodo que los antropólogos enfatizarían se iniciaría con la expansión europea y su objeto de estudio serían las consecuencias generadas por ese proceso. Esa fue la historia que interesó a los antropólogos, pues ella constituía el pasado inmediato de las comunidades que estudiaban en el presente etnográfico. De otra parte, la historia misma hasta entonces había ignorado las exploraciones hechas por estos especialistas.

Históricamente, la antropología le debe su posición al hecho de haberse ocupado principalmente de gentes que fueran consideradas por un largo tiempo como marginales e irrelevantes para los propósitos de la civilización. Esta experiencia permitió que los antropólogos adoptaran una posición privilegiada al comparar gentes a lo largo de un gran espectro, tanto dentro como fuera de las fronteras establecidas por las personas que hablaban en nombre de la modernidad (Wolf, 1999: I9).

Los antropólogos al abandonar la idea de las comunidades aisladas, distanciadas del mundo, para reconocer que estas eran y habían sido parte de la historia, abrían una nueva área de trabajo ${ }^{8}$.

8. Un buen ejemplo de ello son dos textos de Eric Wolf (I982, I959).

9. Una de las confrontaciones más interesantes en este sentido es aquella entre Obeyesekere (I992a, I992b) y Sahlins (I995).
Esta ruta no estaba exenta de confrontaciones; surgían versiones e interpretaciones del pasado enfrentadas, contradictorias ${ }^{9}$. A pesar de ello la experiencia adquirida en el estudio de la cultura ofrecía gran potencial para aproximarse a la historia. Dice Sahlins:

El problema es ahora explotar el concepto de historia con la experiencia de los antropólogos en la cultura. Por tanto, las historias oscuras de islas remotas merecen un puesto junto a la auto contemplación del pasado europeo -o la historia de las civilizaciones- por su destacada contribución al entendimiento histórico (Sahlins, 1983: 534).

Una transformación semejante se dio en países como Colombia. Sin embargo, allí los énfasis fueron el resultado de influencias muy diferentes. Dice Pineda:

La influencia de las antropologías latinoamericanas, el marxismo y la renovación del pensamiento histórico en la década del setenta en Colombia -en lo que ha sido llamado la Nueva Historia- nos sensibilizó frente a la Historia, ante la necesidad de enfocar nuestros 
problemas con una perspectiva histórica y regional, en un momento en el cual la mayoría de los colegas "extranjeros" que trabajaban en las tierras bajas proseguían en gran parte con unos lentes -como se dijo- en gran medida sincrónicos y enfocados en la comprensión de la dinámica tradicional (Pineda, 2005: 128).

Los datos de unos y otros mostraban historias locales que dejaban ver las diversas relaciones internas y externas de las pequeñas comunidades ${ }^{10}$. Así resultaron evidentes algunos contrastes con los etnólogos-etnógrafos extranIO. Véase Hugh-Jones (I98I), para el Vaupés; y Rappaport (2000), para un caso andino. jeros: el mundo indígena, como el presente que estudiaban los antropólogos en sitios como Colombia (véase Correa, 2006) y su historia (i.e., Gómez, 2006, 2005), revelaba relaciones asimétricas que eran un producto histórico. Esto hacía que los antropólogos locales asumieran una posición comprometida. Dice Correa:

La inserción de los antropólogos en la realidad del país no sólo buscó develar la diversidad social y cultural y su posición al interior de la sociedad nacional, sino que muy pronto se evidenció la estrecha dependencia de las relaciones internacionales y cómo la expansión del capitalismo se lleva a cabo por vía de la imposición de relaciones sociales asimétricas bajo las cuales incorpora vastas poblaciones del mundo, lo que obligó la interpretación de las poblaciones y culturas indisolublemente ligadas a las relaciones regionales e internacionales (2006: I8).

Para entonces los arqueólogos habían construido un mundo distanciado de estas problemáticas. En las orientaciones arqueológicas florecía la construcción de una historia cultural que intentaba delimitar territorios pre-hispánicos, caracterizados por una cultura material -cerámica y orfebrería-, que se podían asociar con las ocupaciones registradas por los cronistas y demás relatores tempranos. Si bien la introducción y el uso de métodos cronológicos de datación absolutos permitía entender la variabilidad espacial y ampliar la temporalidad de estas ocupaciones, se trató de un pasado incapaz de ver al indígena del presente y los conflictos que aquejaban a las comunidades como parte del continuo histórico que se estudiaba. Esta ceguera hacía de los arqueólogos el "ala" reaccionaria de la antropología.

Una nueva tendencia es evidente a finales del siglo pasado y la primera década del veintiuno en los trabajos de algunos antro- 
pólogos, y particularmente en aquellos que trabajan en las tierras bajas orientales sudamericanas. Esta revela un renovado interés por la historia. Algunos investigadores se interesaron por la historia a partir de los desarrollos de la ecología histórica (i.e., Rival, 2002), un innovador programa de investigación que destaca las acciones humanas como un aspecto central en una historia ambiental y social de todos y cada uno de los grupos humanos (Balée, 2006). Otros la reconocieron como una parte fundamental de la forma en la cual era entendido el paisaje por los nativos (i.e., Reichel-Dolmatoff, I996; Santos-Granero, 1998), o la emplearon en relación con la etnografía para entender formas organizativas pretéritas (i.e., Vidal, 2003). Es dentro de esta tendencia que algunos más han intentado vincular el relato histórico de esos otros con las visiones construidas por los occidentales sobre el pasado (i.e., Franky, 2006). Desde estas perspectivas resultan evidentes nuevas oportunidades para establecer un fructífero diálogo entre antropólogos y arqueólogos, como lo sugiere la reciente propuesta de Goulard (2006). A pesar de ello, son evidentes algunos peligros derivados de uso de los conceptos empleados por unos y otros antropólogos, de los que hablaré más adelante.

\section{Arqueólogos}

Willey y PhILLIPS (I958: 2), HACE YA UN TIEMPO, AFIRMARON QUE LA ARqueología o es antropología o no es nada. Esta es una afirmación con la cual un gran número de arqueólogos latinoamericanos estuvieron y están de acuerdo. Después de todo, la misma equivale a admitir que antropólogos y arqueólogos estudian una misma cosa, aun cuando desde diferentes puntos de vista ${ }^{11}$. Así

II. Por ejemplo Binford (I962) veía a la arqueología como una parte de la antropología. Para él, el propósito de la antropología era explicar las semejanzas y diferencias en la totalidad del lapso temporal y espacial de la existencia humana. es posible reducir, si es que esto se puede considerar una reducción, sus estudios al funcionamiento y las transformaciones de las sociedades en el tiempo (sincronismo-diacronismo). Para muchos hoy, como en el pasado, este eje constituye un punto focal de estos dos campos de la antropología (i.e., Jones, 2003).

Esta concepción de la arqueología, como antropología, ha permitido que la arqueología se involucre en un amplio rango de 
problemáticas al verse forzada a participar en un interminable contrapunteo con respecto a los enfoques y datos generados por los antropólogos. Imposible negar que esta relación estimula el desarrollo y pone a prueba nuevas ideas. Así se han enriquecido los enfoques generados, al tiempo que se crea una base sólida para las discusiones en el seno amplio y diverso de la disciplina antropológica.

Es cierto que los arqueólogos han estado más cerca de la historia en aquellos lugares donde quienes practican la arqueología ven relaciones directas entre sus sociedades y las que ellos estudian, por ejemplo, Europa (véase Trigger, 1989: 372). Sin embargo, en las Américas y bajo la tutela de la arqueología estadounidense se privilegió su participación en el ámbito antropológico; así los arqueólogos reconocían y destacaban la filiación entre las sociedades estudiadas por los antropólogos y por ellos mismos. El hecho de ubicar a los habitantes del pasado en cercanía de los exóticos del presente tuvo y tiene importantes connotaciones en la definición de las identidades nacionales en Latinoamérica. En muchos países de la región el componente indígena era, al menos numéricamente, más grande que el europeo o africano. A pesar de ello, la identidad que se buscaba construir requería de la separación de los logros indígenas del pasado, que en muchas regiones contrastaban con la precaria situación presente de esas poblaciones. Era necesario entonces resaltar otros valores y formular nuevas formas de acercamiento a este pasado para satisfacer las necesidades del presente. Las respuestas fueron múltiples ${ }^{12}$.

La antropología colombiana no ha sido una excepción en estos aspectos. Allí la arqueología se ha desarrollado bajo la tutela de la antropología. Prueba de ello son los planes de estudios de pregrado de los cuatro departamentos de antropología más antiguos del país: universidades de los Andes (Bogotá) ${ }^{13}$, de Antioquia (Medellín) ${ }^{14}$, del Cauca (Popayán) ${ }^{15}$ y Nacional de Colombia (sede Bogotá) ${ }^{16}$. Actualmente, en estos programas es evidente una clara tendencia a la percepción y organización de la antropología en el clásico esquema de los cuatro campos: antropología social-cultural, antropología física,

I2. Un ejemplo de papel de estos valores, en el caso del Perú, se encuentra en Molinié (2004).

I3. http://antropologia.uniandes.edu.co/

I4. http://antares.udea.edu.co/antropologia/ pensum.htm

I5. http://humanidades.unicauca.edu.co/index. php? $x=$ plan_antropologia\&tit=antropologia

I6. http://www.humanas.unal.edu.co/antropologia/index.html 
arqueología y lingüística, propio del antiguo modelo de la antropología estadounidense, pese al notorio abandono o descuido de la lingüística en general. En Colombia esta inclusión de la arqueología en la antropología, dándole la espalda a la historia ${ }^{17}$, contribuyó a crear nuevas alternativas para abordar el problema

I7. Langebaek (2004) plantea el distanciamiento entre arqueología e historia en Colombia en términos de desacuerdos insalvables entre ciertas formas de hacer arqueología y ciertas formas de hacer historia. Para él las razones para el surgimiento de estos obstáculos se encuentran en el desarrollo histórico de estas disciplinas, así como en los preconceptos de arqueólogos e historiadores sobre el oficio del otro. de la identidad. Allí se facilitó un discurso que resaltaba la multiplicidad, como una diversidad poco específica (véase Pineda, I994), dado el distanciamiento entre la arqueología, ocupada del periodo prehispánico, la historia, encargada del lapso que se iniciaba con el descubrimiento y conquista, y la antropología, ocupada del presente. Así, los antropólogos sociales cobraban una importancia inusitada al transformarse en expertos en la diversidad del presente. Tenían una enorme responsabilidad frente a la nación. A los arqueólogos les quedaba el oficio de llenar las bodegas de los museos de objetos antiguos, e ilustrar el pasado con la ayuda de mapas.

$\mathrm{Al}$ estructurar la disciplina bajo el esquema generado por la antropología estadounidense resultó axiomático que el saber etnográfico y etnohistórico constituyeran los pilares en la formulación, la descripción y el análisis del pasado del que hablan los arqueólogos. En manos de distintos investigadores, estos materiales han posibilitado la identificación de atributos, registrados en diferentes épocas, con los cuales es posible "descifrar" el pasado, o al menos imaginarlo dándole realidad a algo que de otra forma difícilmente la tendría. Así se ha "asegurado" el acceso a algunos aspectos de las sociedades que existieron en tiempos remotos, haciendo del pasado un espacio más conocido, más cómodo.

La herramienta por excelencia para promover estas conexiones, tanto por parte de la nueva arqueología estadounidense, como por la arqueología colombiana, ha sido la generación de analogías. Efectivamente, diversos autores desde la época de los anticuarios emplearon analogías derivadas del presente (etnografía) o del pasado inmediato (etnohistoria-historia), haciendo de ellas un componente esencial de su forma de concebir el pasado (véanse Orme, I974; Peregrine, 200I, 2004; Stahl, 1993). No obstante, las estrategias con las que se vinculan pasado y presente han variado profundamente. Algunas de estas conexiones se emplearon para 
ilustrar aspectos de sociedades pretéritas tales como su organización, para sugerir procesos de transformación, para entender el funcionamiento particular de algunos artefactos, o fueron la base para edificar los tipos de sociedades que sustentaron los esquemas evolucionistas, tanto en los inicios de la antropología como en sus desarrollos posteriores. Por ello, a lo largo de la historia de la arqueología el uso de estas analogías basadas en el presente ha generado formas contrastantes, mundos opuestos, distanciados por perspectivas conceptuales dispares.

Sólo a partir de la década de I950 los arqueólogos que practicaban lo que ha sido denominado como una arqueología internacional se ocuparon seriamente de desarrollar métodos sistemáticos para el empleo de los datos etnográficos en la interpretación de informaciones arqueológicas (i.e., Gould y Yellen, r991; Gould y Watson, I982; Stiles, 1977; Wylie, I985a, I985b). Muchos de estos arqueólogos identificaron problemas asociados con el dato etnográfico, dada la documentación del mismo por parte de los antropólogos. Eran evidentes las carencias y desinformaciones cuando se intentaba usarlo para entender problemas arqueológicos. Esta dificultad, sumada a la necesidad de un refinamiento de la información, así como al deseo de orientar la mirada hacia aquellos puntos que son más críticos en sus modelos, los llevó a proponer el desarrollo de la etnoarqueología (Nicholas, 200I). A pesar de ello, el puente establecido gracias al uso de fuentes etnográficas para generar analogías permitió desarrollar y aplicar conceptos relativos a la adaptación humana, aspecto fundamental de la arqueología sistémica. Esta es una conexión que ha persistido en muchos estudios y cuyo valor es reconocido por pensadores de las más variadas tendencias (i.e., Binford, I978; Odre, I986). Hoy, el uso de las analogías fundamenta en buena parte el desarrollo de algunos aspectos de las diversas arqueologías, que surgieron a partir de la década de 1980. Desde los años 1960 la analogía tiene una posición destacada en el "middle range theory" (teoría de rango medio), que se mantiene como una herramienta básica en el trabajo de muchos de los arqueólogos del siglo veintiuno. Si bien esta relación basada en la definición de la arqueología como un campo de la antropología ha sido muy beneficiosa, también involucra algunos aspectos problemáticos. 
VISIONES PRESENTE-PASADO, PASADO-PRESENTE：ANALOGÍAS

Lel

EMPLEO DE ANALOGÍAS ETNOGRÁFICAS PARA ENTENDER EL PASADO, EXPLICAR

el presente o normalizarlo crea problemas con características específicas, de acuerdo con los marcos de referencia en los que se produjeron y emplearon. Unos pocos ejemplos sirven para ilustrar lo anterior. Un caso lo constituyen las afirmaciones y las discusiones derivadas de los prototipos creados a partir de los datos etnográficos para dar cuenta de las diferentes formas de liderazgo. Al proponer estas categorías -i.e., grandes hombres, jefes- autores como Sahlins (I990) esperaban hacer generalizaciones con validez, tanto para el pasado como para el presente etnográfico. Sin embargo, al definir estas categorías se obviaron importantes aspectos como su representatividad, su ubicación en un contexto colonial desde el cual eran descritas, y la confiabilidad de las fuentes empleadas en su formulación. Esto contribuyó a que no coincidieran, por sus características o por sus contextos de ocurrencia, con las realidades que supuestamente constituían. Su aplicación al pasado creó un espacio más concreto, aun cuando indudablemente más problemático. Estos prototipos alimentaron, simultáneamente, una teoría general del cambio cultural. Me refiero al evolucionismo, obviado el estudio de las relaciones sociales y de poder con sus representaciones -i.e., rituales, uso del espacio social y económico- que sustentaban estas categorías (véase Roscoe, 2000). Dos problemas parecen obvios. Por una parte, la existencia de semejanzas entre situaciones etnográficas y rasgos arqueológicos alimentó reconstrucciones que fueron mucho más allá de aquello que parecía explícito en las convergencias señaladas. Por otra, se omitió el estudio de otros aspectos importantes al aceptar lo exacto y apropiado de los prototipos; sin duda, este es el caso del cacique guerrero propuesto por Carneiro (I990, I998), del cual hablaré luego.

No menos incierta ha sido la aplicación de modelos arqueológicos para contextualizar observaciones etnográficas. Su uso ha permitido que se le otorgue un valor desproporcionado a algunos aspectos. Por ejemplo, en la amazonia la temporalidad y la estabilidad que algunos asumen para cierto tipo de organización se construye partiendo de un supuesto que se alimenta del registro etnográfico para iluminar el pasado, y que a su vez reafirma el presente. En esta región un modelo de organización social, que 
se refleja en la definición y el uso del espacio doméstico y se relaciona con las viviendas comunales -malocas, principalmente- se asumió como estable o al menos de larga permanencia a lo largo de los tiempos (véase Reichel, E., 1987). Sin embargo, ningún arqueólogo, hasta donde sé, ha excavado o reportado la excavación de la planta de una maloca o de cualquier otro tipo de casa comunal de cierta antigüedad en la amazonia. Así que no existen datos empíricos respecto al uso del espacio en estas supuestas malocas del pasado. El uso del espacio de forma comunitaria, como aquel que se verifica en la maloca y que es propio de una sociedad igualitaria, implica problemas en la sectorización del espacio, que deben ser abordados para comprender el cambio cultural. Esto es especialmente cierto si algunas de estas sociedades entraron en procesos de complejización, como parecen sugerirlo algunos investigadores ${ }^{18}$. Es innegable que el uso del espacio constituye un importante indicador de las transformaciones históricas, en el ámbito arqueológico, cuyo análisis es muy complejo y ha sido tratado de forma banal en la arqueología colombiana ${ }^{19}$.

En breve, aceptar de manera poco crítica la permanencia del "modelo maloquero" implica obviar el problema del cambio social y negar la posibilidad de cualquier proceso que tienda a la complejización. Es evidente que este raciocinio se basa en I8. Este aspecto de la complejización ha sido central en la arqueología amazónica. El mismo va desde las argumentaciones iniciales de Betty Meggers (1957), pasando por Lathrap (I970), Roosevelt (1987) y Heckenberger (2002), para mencionar sólo algunos casos.

I9. Para la arqueología colombiana un análisis crítico de algunas de las interpretaciones derivadas del estudio de las viviendas arqueológicas, con ayuda de informaciones etnográficas, se encuentra en Langebaek (1997). una apreciación derivada de una situación del presente que adquiere un valor ponderado al extenderse sobre el pasado. Este valor depende de las premisas empleadas para sustentar concepciones específicas del cambio cultural y la capacidad de las sociedades para "recordar". El estudio en las sociedades ágrafas de la estabilidad, la permanencia y la flexibilidad de la tradición oral es una cuestión que requiere de un escrutinio cuidadoso, el cual es obviado por los antropólogos de forma regular. No se pueden asumir, como un acto de fe, la persistencia y validez de estos relatos, como tampoco se pueden descartar argumentando a priori su inocuidad. Al aceptar de manera poco crítica las historias orales contribuimos a generar y reforzar realidades cuyo contenido es de difícil constatación y de escaso valor explicativo. Así la contextualización etnográfica 
reduce la potencial visibilidad arqueológica, aun cuando reafirme una supuesta estabilidad para un sistema social que fuera registrado por los etnógrafos del siglo veinte.

Dada la diversidad de formas de construir estas "conexiones" entre el pasado y el presente, es necesario seleccionar sólo unas cuantas entre ellas para explorar cómo operan. Trataré aquí únicamente la construcción de analogías etnográficas para ilustrar

20. Me refiero aquí a los modelos basados en ideas evolucionistas, muy populares en la década de 1960 y 1970 como parte del desarrollo de la "nueva arqueología" estadounidense. Algunas tendencias arqueológicas en el nuevo siglo ven en la identificación de ciertos comportamientos claves para entender la evolución humana como parte de una transformación social. Por ejemplo, Bingham (2000). el pasado. Dejo de lado, por el momento, el problema del funcionamiento y el de las analogías para crear prototipos referidos a categorías amplias para organizar la información en secuencias organizativas $^{20}$, y me concentro en el uso de algunas de las analogías etnográficas que han tenido más impacto en la reconstrucción y el uso del pasado por parte de antropólogos y arqueólogos en Colombia.

\section{El pasado ilustrado: analogías, visiones y estructuras}

LA UTILIZACIÓN MÁS CORRIENTE DE LA ANALOGÍA ETNOGRÁFICA, USO QUE POR demás es muy popular en Latinoamérica, es aquella que Stahl (I993) ha denominado como la "analogía ilustrativa". En este tipo de analogía los materiales etnográficos e históricos constituyen la base que le da cuerpo y vida a un reducido número de objetos arqueológicos, al transformarlos en parte de un relato. De esta forma es posible establecer un marco de referencia amplio, a pesar de que la narración se basa en la comparación de objetos materiales específicos, estrategia de uso corriente en los marcos de referencia creados por las historias culturales. En Colombia, desde muy temprano se empleó esta herramienta en el estudio del pasado. Por ejemplo, Restrepo (IgO3) siguió este procedimiento para contextualizar algunos movimientos de población, asociando los mismos a ciertos conjuntos de materiales que consideró característicos de conjuntos culturales específicos.

Una segunda manera de emplear este tipo de ilustración es hacer referencia a aspectos no materiales como el rango. De una 
u otra forma el procedimiento consiste en reconocer, a partir de objetos arqueológicos, que son comparados con materiales y datos etnográficos, semejanzas que permiten aproximarse a los fragmentarios contextos sociales pasados. Un claro ejemplo de este procedimiento en la arqueología colombiana se encuentra en Uribe (véase Uribe y Cabrera, I988). Uribe hizo una sugerencia provocativa sobre la concepción y el uso del espacio a partir de un cementerio protopasto, estableciendo una analogía con las informaciones etnográficas y documentales aportadas por Rappaport (I988a, I988b) para una región del sur de Colombia. El uso de esta estrategia también ha permitido a algunos investigadores plantear hipótesis sobre algunos rasgos cosmológicos ${ }^{21}$.

De una u otra forma en esta construcción el pasado y el presente se funden en el artefacto. Es por medio de la voz del cronista, viajero o los nativos que hablan por medio del antropólogo, o a quienes el antropólogo cree representar cuando habla, que se infunde nueva vida a las "cosas", al proveerlas con un contexto am-

2I. En este sentido, para el caso colombiano, son de interés los trabajos de Ann Osborn (I985) y Reichel-Dolmatoff (I988), del cual hablaré posteriormente. plio. Así, los artefactos dejan de estar separados de los humanos que los fabricaron y emplearon, para cobrar vida en actividades concretas.

Este procedimiento no sólo ha sido corriente en la reconstrucción académica del pasado. El mismo constituye el eje central de la representación que se realiza en el museo. Allí se fantasea un espacio vivo, aun cuando "petrificado", para el pasado a partir del presente. Esta representación tiene la indiscutible ventaja de normalizar el ayer, forzando su aceptación por parte del espectador como una realidad "palpable". De este modo, la exhibición del museo no cuestiona lo ocurrido, sino que lo trivializa a partir de su normalización al presentar lo "sucedido" de una forma ordenada y aceptable. Evidentemente, algunos museos han asumido la pasividad del observador, quien se encuentra en una posición desventajosa ante el conjunto de expertos que el museo emplea para crear la exhibición. La autoridad de los peritos tiende a permanecer sobre la de los demás. Por esta ruta, el oficio de la representación museográfica de la mano de la analogía es la imposición de un pasado-presente normal, incuestionable. Pasado cuyos significados no siempre son asimilados por los visitantes; entendimiento reemplazado, en muchos museos, por el artificio mismo de una representación estética que maravilla. 
Sin embargo, cuando el público no especializado confronta el objeto arqueológico se evidencian otras visiones, muchas veces opuestas $^{22}$.

En Colombia, desde la segunda mitad del siglo veinte, museos como el Museo del Oro del Banco de la República privilegiaron la aproximación al pasado en compañía de la voz del cronista para conectar los diferentes tiempos. Allí, de forma regular las crónicas de la conquista, así como los documentos tempranos, suplantaron la voz del "nativo etnográfico", permitiendo que predominara el "nativo histórico", quien habla por medio de sus traductores: cronistas, viajeros, aventureros. Este es un artificio corriente para dar cuerpo a las sociedades pre-contacto. En este contexto, la etnohistoria cobró una destacada posición en la elaboración arqueológica y antropológica. De este modo museógrafos y antropólogos-arqueólogos traspasaron el umbral de los tiempos. Hoy, algunos consideran que con este ejercicio se contribuye a la recuperación de los hilos culturales que, conectándose a través de los siglos, permiten la definición de identidades, que es una preocupación actual de los antropólogos ${ }^{23}$.

El predominio del "nativo histórico" sobre el "nativo etnográfico" en el museo colombiano del siglo veinte probablemente se encuentre en el profundo

22. Véase Programa de Voluntariado Universitario (2007).

23. Recientemente un antropólogo ha empleado una perspectiva histórica para señalar diversos aspectos de una antigua sociedad del territorio colombiano para contribuir, en parte, "a tejer esos hilos de raigambre cultural que proyectándose en las gentes actuales hunde sus raíces en el pasado" (Correa, 2004: 25). desprestigio del indígena en una sociedad en la cual predominan los valores de clase asociados y confirmados por el origen social de los individuos. Después de todo "indio" sigue empleándose en el país como un vocablo despectivo, un terrible insulto. Esta visión contrasta con la del indio del siglo dieciséis, que fuera presentada por algunos autores, desde épocas muy tempranas, como una inspiración ante la dominación, un ejemplo de lucha (véase Langebaek, 2003). Posiblemente por ello, también, en las historias culturales colombianas se resaltó el "nativo histórico" en detrimento del "nativo etnográfico".

De forma particular el uso del dato etnohistórico ha sido corriente desde la década de 1960 en la antropología de corte estadounidense, cuando se permitió que se transformara en un símil del dato etnográfico. 
La etnohistoria tiene dos intereses principales que han sido denominados etnografía histórica e historiografía de las culturas que no tuvieron una escritura. La etnografía histórica es la reconstrucción de una descripción etnográfica sincrónica de un estadio pasado de una cultura, especialmente soportada por documentos contemporáneos con ese estadio (...). El propósito es producir una descripción paralela y tan cercana como sea posible a aquella producida en el campo de la etnografía, a pesar de que las evidencias no son aquellas que el antropólogo ha observado, escuchado o que le fueron mencionadas, sino lo que otros, que no son antropólogos, aprendieron y consignaron en documentos (Sturtevant, I966: 7).

En este contexto, la etnohistoria puede ser vista como un punto focal hacia el cual convergían la etnografía, la arqueología y la historia. De alguna manera el tiempo, delimitado por los documentos, se transforma en el eje y la coyuntura que permiten la conexión entre diferentes momentos y entes sociales para crear una continuidad que da sentido al pasado y al presente.

La inclusión y el énfasis del dato etnohistórico en los estudios realizados en Latinoamérica no sólo se puede atribuir a su riqueza o al uso que algunas sociedades, o sectores de ellas, hicieran para manipular y sobresaltar ciertos valores por razones políticas e ideológicas (véase Patterson, 1994). El mismo se justificó en el reconocimiento de las carencias de la información arqueológica, problema al que comúnmente se le ha atribuido la pobreza del pasado, obviando las deficiencias en los modelos que hacen coherentes o incoherentes los datos (Flórez et al., 1997). Para el caso de la arqueología colombiana esta justificación se utilizó prácticamente desde sus inicios. Por ejemplo, Trimborn afirmaba:

Los intentos de un examen histórico retrospectivo del desarrollo cultural colombiano han de basarse, por tanto, en el análisis de los hechos que reflejan la situación en la época de la conquista española y en los hallazgos de las excavaciones que sólo en los últimos tiempos se han practicado metódicamente (I949/2005: 78).

El uso de este dato documental llevó, en la mayoría de los casos, a la aceptación de algunos presupuestos. Entre ellos está el suponer que antes del contacto las culturas nativas gozaban de gran estabilidad, idea comúnmente aceptada desde el siglo diecinueve (Trigger, 1982b). En esta historia el cambio cultural 
se atribuía a fuerzas externas, como había sido común en las visiones que del pasado se desarrollaron en otras áreas. Dice Trimborn:

Las condiciones culturales, incluso dentro de cada uno de los grandes grupos, no eran uniformes. La causa hay que buscarla en la variabilidad interna de las formas de vida de un pueblo, cuyo campo de actividades se halla en función de las fuerzas formativas externas que actúan sobre él. Entre estas fuerzas formativas, aparte de las condiciones geográficas radicalmente distintas de cada parte del territorio, las diversas influencias extrañas procedentes de varias direcciones desempeñaron un papel de la misma categoría que los procesos de estratificación histórica, cuya vinculación a determinados pueblos y grupos lingüísticos aún no ha sido resuelta (I949/2005: 83).

Así, el tiempo anterior al contacto con los europeos se comprimía y resumía en la representación que llegaba mediante las descripciones que daban vida al pasado. Indudablemente esto imponía, de una u otra forma, la ficción de cierta uniformidad en el pasado.

A pesar de todo lo anterior, algunos investigadores colombianos reconocían problemas en las categorías derivadas de las informaciones etnohistóricas. Estas eran evidentes, principalmente, en la construcción o identificación de culturas regionales. Emergían dificultades para conectar el mundo alcanzado con la información etnohistórica y aquel que era posible registrar arqueológicamente. Por ejemplo, decía Llanos, refiriéndose a los quimbaya.

Los quimbayas, desde el punto de vista de su identidad étnica, se hallan entre los grupos menos investigados por los arqueólogos. Es mayor y más rica en detalles la información de la guaquería que la de la arqueología. No existe ni periodización histórica ni clasificación de sus objetos, como consecuencia de excavaciones científicas. Técnicamente sólo se han excavado unas pocas tumbas, cuyos resultados son insignificantes si se piensa en los centenares de entierros guaqueados. Apenas hay unas cuantas dataciones de C-I4, y recientemente se están estudiando los sitios de vivienda que comienzan a despejar el complejo mundo cultural precolombino regional (I986: 78).

Veinte años después este problema persiste, dado que la falta de conocimiento sigue siendo atribuida a la precariedad del dato empírico. 
En Colombia, en las últimas décadas del siglo veinte y principios del veintiuno la selección del "informante" empleado para ilustrar el pasado cambió. La publicación de algunos textos en los cuales el dato etnográfico se empleó para establecer conexiones con los mundos vividos en el pasado, apoyándose en el análisis de materiales arqueológicos -i.e., colecciones orfebres-, permitió crear visiones de carácter integral asociadas a cosmologías generales ${ }^{24}$. En efecto, los conocimientos etnográficos de Reichel-Dolmatoff al ser empleados para una lectura de los objetos arqueológicos del museo garantizaron a los futuros visitantes de este un pasado diferente. Así

24. El texto que ha producido la mayor influencia en este sentido es "Orfebrería y chamanismo", de Gerardo Reichel-Dolmatoff. La nueva exposición del Museo del Oro, inaugurada a principios de este siglo, se basa en estas ideas.

se transformaron la presentación y el contenido del pasado. A pesar de que este tipo de conexión entre lo que estudiaban los arqueólogos y el dato etnográfico era común para entonces en otras regiones, en Colombia había tenido un carácter marginal.

Ciertamente, en aquellos lugares del mundo en los cuales existe una continuidad significativa entre los tiempos pre-históricos y el presente etnográfico, los arqueólogos ven los descubrimientos de los etnógrafos como una parte importante e integral en el continuo de aquello que ellos estudian. Este punto de vista fue fundamental en la aproximación histórica directa, que fuera ampliamente usada en la interpretación de informaciones arqueológicas (Trigger, I982a: 3).

En el caso colombiano el empleo de esta estrategia no quiso decir que se abandonara la herencia conceptual que había dejado el uso durante algunas décadas de la noción de cultura, construida a partir del dato etnohistórico. Las nuevas representaciones combinaron componentes de uno y otro sistema, proporcionando un contexto para un buen número de objetos, cuya procedencia o asociación eran difíciles de determinar -gran parte de las colecciones arqueológicas de la mayoría de los museos colombianos proviene de excavaciones ilícitas y, por tanto, carece de informaciones asociadas-. De este modo fue posible organizar el espacio en el marco de aquello que se había definido como culturas locales -i.e., quimbaya, tairona, muisca- adicionando un componente cosmológico que ubicaba el relato, por decirlo de alguna manera, fuera de todos los tiempos. La presente estructura y montaje del Museo del Oro encarna esta visión (véase Rodríguez, s. f.). 
Como se puede ver, la utilización de estas analogías para ilustrar el pasado requiere de vínculos geográficos. En este caso la continuidad constituida por una cultura compartida, o la sospecha de una filiación histórica, permite conectar diferentes momentos a partir de la identificación de semejanzas entre aquello que se conoce -sociedades específicas- y aquello que resulta desconocido -el fragmentario registro arqueológico-. El encadenamiento histórico es un axioma en este punto de vista (véase Trigger, I982a, 1982b). Así se edifica lo que Sturtevant (I966: 9) denominó como la aproximación histórica directa al pasado. Entre mayor sea el conocimiento histórico de las ligaduras entre las sociedades que se conectan a lo largo del tiempo, más confiable serán los resultados (véase Ascher, 196I). Sin embargo, estas analogías encierran una limitación geográfica, dado que implican la definición de un espacio restrictivo, dentro del cual se ajustan los elementos que se intenta hilvanar. Evidentemente el tiempo ha transformado las sociedades que se relacionan; a pesar de ello se presupone la existencia de constantes detectables espacialmente -región, área-, tanto en el texto -crónica, etnografía o relato- como en su contraparte del registro arqueológico. Entonces, la solidez de las interpretaciones derivadas estará avalada por un conjunto de supuestos de orden histórico definidos a partir de un "estrecho" y parcializado vínculo cultural. En el caso colombiano es claro que este enlace se encuentra en la idea de "cultura" y su derivado -área cultural, área orfebre-. Así, una geografía compartida entre el ayer y el hoy da significado a la historia y permite su normalización en el museo.

En general, en todas las regiones del continente en las cuales se empleó esta aproximación que privilegió el dato histórico se asumió que con anterioridad a la irrupción de los europeos en el nuevo mundo el cambio cultural había sido extremadamente pausado. Esta suposición hacía de los documentos tempranos una "imagen" apropiada del pasado, representación que era posible extender de forma casi indefinida en el tiempo anterior al contacto. Esta aproximación minimiza importantes factores, creando una confianza artificial en los documentos empleados. Por ejemplo, se restaba importancia a las dimensiones y la velocidad del impacto ocasionado por el contacto entre el viejo y el nuevo mundo. Las epidemias desatadas en el siglo dieciséis viajaban, en algunas regiones, mucho más rápido que los mismos europeos que las habían introducido (Cook, I998; Ramenosfsky et 
al., 2003), factor que se omitía al dibujar un mundo prístino y ajeno a occidente. Igualmente, la irrupción europea y africana en las Américas llevó a la supresión de algunos poderes tradicionales, así como al surgimiento de nuevas expresiones del mismo. Así, tan solo unos pocos años después del contacto inicial, surgían nuevas formas organizativas, que a pesar de ello eran consideradas como tradicionales por quienes empleaban los documentos para ver el pasado (véase Whitehead, 1999). Esto permitió que muchos antropólogos hablaran de cacicazgos, asumiendo cierta estabilidad histórica, cuando en realidad sólo estaban frente a la formación de pequeñas e inestables estructuras de poder en el proceso de reestructuración de la geopolítica de inmensas regiones. Las sociedades descritas, no obstante lo tempranos que fueran los documentos, ya habían sido afectadas en diferente grado por el contacto ${ }^{25}$.

25. Para un caso amazónico véase Mora (2006), capítulo 5 .

De otra parte, se presuponía que los europeos que realizaban las descripciones tenían un entendimiento más o menos "conveniente" de las parcialidades de las sociedades que consignaban en sus documentos, cuando en realidad muy pocos tenían los mínimos elementos o puntos de referencia para entender lo que veían y describían. Para nadie es un secreto que el etnocentrismo o la objetividad no eran ni pecado ni requisito para quienes describían a esos otros recién descubiertos. Allí se valía todo. La visión eurocéntrica invadió las conclusiones que se obtenían, visión que se desplazaba en el tiempo con el uso inadecuado del dato documental. Pero los potenciales aportes que los documentos tempranos podían hacer no sólo fueron tergiversados por algunos etnohistoriadores: también se comprometió el presente. Muchos etnógrafos, al emplear la visión etnohistórica fuera de su contexto para producir una historia de los grupos que describían, enredaron los alcances del método comparativo que se esmeraban en emplear (véase Trigger, 1982b).

Todos estos problemas llevaron, a partir de la década de 1970, a algunos investigadores en las Américas y particularmente en Norteamérica a cuestionar seriamente el valor de estas analogías (Trigger, 1982b); una profunda desconfianza hizo que algunos rechazaran totalmente las búsquedas ethnohistóricas. El conocimiento etnohistórico encarna y encarnó una enorme dificultad al carecer de una robusta teoría que generara filtros críticos para su manejo. Este vacío deja en la oscuridad a los etnógrafos y arqueólogos que 
intentan emplearlo. Aún hoy, la etnohistoria sigue siendo la cenicienta, al ser comparados sus alcances teóricos con aquellos logrados por la antropología y la arqueología. A pesar de ello, en países como Colombia muchos investigadores, tanto etnógrafos como arqueólogos, persistieron en el uso de estas fuentes obviando los problemas mencionados.

Indiscutiblemente la etnohistoria ha sido sólo una de las fuentes empleadas: algunos antropólogos y arqueólogos han establecido analogías combinando estas con situaciones etnográficas para ilustrar procesos que consideran de importancia en el pasado. Posiblemente la más famosa de estas analogías sea el empleo de datos etnohistóricos y etnográficos que hiciera célebre Robert Carneiro (i.e., I998, 1990). Para él, una actividad muy concreta, la actividad guerrera, constituyó un elemento esencial en la formación de los cacicazgos. De este modo la representación del cacique guerrero fue tomada e incorporada a los modelos que intentaban dar cuenta de la evolución cultural; muchos acogieron estas ideas (i.e., Kelekna, 1998; Redmond, 1998). Es necesario recordar que una propuesta semejante, en la cual se vinculaba la actividad guerrera, las condiciones de producción agrícola y el desarrollo de una mayor complejidad, empleando ejemplos etnográficos de la amazonia, había sido presentada con anterioridad (Vayda, 1969).

Indudablemente la propuesta de Carneiro es atractiva. En Colombia la misma ha sido empleada en diferentes oportunidades para ver qué tanto podría explicar algunos aspectos de registro arqueológico (véase, por ejemplo, Langebaek et al., 2002). Esta propuesta permite entender, o por lo menos aceptar, a los violentos líderes que habitan nuestro pasado, al tiempo que concede un lugar destacado al impetuoso jefe yanomamo del presente etnográfico que describiera Chagnon (I968). Tal vez por esto la imagen del líder guerrero fue capaz de traspasar, en muchos escritos, la línea que separa la realidad de la irrealidad, imagen que se metamorfoseó hasta transformarse en un axioma. Esto ocurrió en el segundo en el cual Carneiro (I998) intuyó el "flashpoint". Así surge un aforismo que llega a las pantallas de los televisores y los telones de los cines para desbordarse desde allí invadiendo el presente. A pesar de que la imagen generada por los medios -i.e., los sangrientos aztecas ${ }^{26}$ - es significativamente diferente de la planteada por los investigadores, su genealogía es indiscutible. En realidad se trata 
sólo de una imagen, una ilustración que pueden emplear algunos investigadores para plantear problemas o edificar hipótesis de trabajo, pero la cual se mueve en el espacio en el que habitan las especulaciones dado que no cuenta con una realidad empírica o una verificación arqueológica. Se trata de una ilusión, un espejismo. A pesar de ello, ahora que está por todas partes es real.

Por otra parte estas representaciones, particularmente las museográficas, actuaron como un mecanismo de exclusión. La visión puesta a disposición en muchos de los museos latinoamericanos, en general, y en particular en los colombianos de hace veinte años, e inclusive las de hoy, dicen muy poco a los habitantes indígenas de las selvas, las llanuras y los montes. Estos, están ajenos a una representación que congrega en torno de una identidad que define lo colombiano, desconociendo el pensamiento que ellos mismos tienen de la historia y que los excluye. Esto es evidente cuando los nativos hablan de la historia (i.e., Matapí y Matapí, I997) o son interrogados sobre el papel de esta en su identidad (i.e., Schlenker, 2003; Vasco, 2002). Indudable: los informantes de los etnógrafos hablan de cosas diferentes de aquellas que se ven en el museo. En realidad no puede ser de otra manera; después de todo muchas de estas representaciones museográficas son construidas desde un punto de vista muy particular que las hace etnocéntricas o al menos muy parcializadas. Obviamente, la realidad histórica a la cual intentan acceder muchas de estas comunidades, como los guambianos en Colombia, es diferente de aquella que es capaz de producir los datos e interpretaciones de los arqueólogos ${ }^{27}$. Esta realidad es parte de un desarrollo histórico y unas luchas y confrontaciones particulares, las cuales el museo, como entidad estatal,

27. Véase Vasco (1992) para el caso guambiano. tendría muy poco interés en exponer. Posiblemente por esto el interés que demuestran algunos investigadores por recuperar y contribuir a generar espacios para que estas historias tengan una posición más destacada (i.e., Gnecco, I999a, I999b, 2002; Ruiz, I999) no ha permeado la representación institucional del pasado en Colombia.

El interés reciente, de principios del siglo veintiuno, por parte de algunos antropólogos por la historia los lleva a las fuentes arqueológicas. Estos antropólogos intentan obviar el distanciamiento temporal existente entre el relato mítico, la historia local y la “creación” de modelos o hipótesis arqueológicas (i.e., Gow, 200I; 
Vidal, 2003), interés compartido con algunos arqueólogos (i.e., Heckenberger, 2005, 2002; Zucchi, 2006). Un ejemplo reciente de esta aproximación se encuentra en Franky (2006). En esta oportunidad se trata de una reconstrucción de la ocupación del noroeste amazónico. Franky considera los planteamientos realizados por diferentes investigadores -Nimuendajú (1950), Lathrap (I970), Reichel-Dolmatoff (I997), Zucchi (2002)-, y contrasta estas ideas con informaciones etnográficas para descifrar las rutas de desplazamiento de algunos de los grupos de esta sección de la amazonia. Estos datos son considerados dentro del marco producido por la información lingüística. Un procedimiento semejante emplearon y emplean algunos arqueólogos (i.e., Lathrap, 1970). Estos arqueólogos definieron las rutas a partir de la distribución de "tradiciones" cerámicas, que fueron hipotéticamente correlacionadas con grupos lingüísticos. Sin embargo, estas correlaciones demostraron no ser tan sólidas como se asumió en un principio. De manera semejante, la definición de los conjuntos cerámicos se basó en parámetros tan amplios que para muchos no ofrecen garantías en términos de las conexiones culturales que revelan (Mora, 2006).

Detrás de estos modelos de desplazamientos se encuentra un esquema difusionista que no explica los movimientos, por mucho permite trazar rutas hipotéticas para ellos. Obviamente estudiar esto no es el propósito de antropólogos como C. Franky, quienes desean abordar el problema de las continuidades y discontinuidades históricas. Sin embargo, estos modelos son sólo planteamientos hipotéticos que requieren de una prueba, lo cual se ha dificultado tanto por el tipo de evidencias que los soportan como por algunos problemas inherentes a los modelos y los supuestos sobre los que se edificaron -i.e., condiciones ecológicas, proliferación de guerras, formación de sociedades complejas, expansión política- (véase Mora, 2006). Por ello, tratar de usar estos modelos como realidades visibles mediante los datos etnográficos implica que el relato mítico ha salvaguardado la realidad que describe por algunos milenios sin alteración, y que estas reconstrucciones arqueológicas son mucho más que hipótesis. Dos suposiciones, que por su naturaleza, hacen frágil la conexión que se pretende mantener.

De otra parte, la construcción de prototipos de sociedades -i.e., cacicazgos o los líderes que fueran mencionados con anterioridad-, basados en datos etnográficos, en otras latitudes 
constituyeron sistemas para poner a prueba hipótesis de trabajo. En Colombia, por el contrario, fueron un componente más de la ilustración del pasado.

En el caso de los evolucionistas del siglo diecinueve el énfasis se puso en unos cuantos rasgos que se reconocían en esos "otros" que se ubicaban en sitios distantes y cuyas sociedades podían contribuir a definir conjuntos atemporales. El dato etnográfico, si es lícito llamar las informaciones con las que trabajan de ese modo, constituía un ejemplo del pasado-presente que emergía y se fundía en las exóticas comunidades que descubría occidente. Así nacía, a partir de la expansión europea, un catálogo de antiguas formas que llenaban y unificaban el pasado a partir de una sistematización que consideraba un reducido número de variables.

El siglo veinte produjo otros modelos, inspirados en la consideración de una manera sistemática de las informaciones etnográficas. Los trabajos de Irving Goldman (I970) y Marshall Sahlins (I990), así como las elaboraciones de Morton Fried (I967), entre otros, resultaron fundamentales en este sentido. Para la década de I980 la gran mayoría de los antropólogos había abandonado estas ideas, incluyendo algunos de sus más destacados proponentes, como Sahlins. Sin embargo, las mismas alcanzaban gran popularidad en los trabajos arqueológicos. Una razón que explica este fenómeno es que estas categorías facilitaban la sistematización de las informaciones, pero esto mismo las llevaría con el tiempo a convertirse en camisas de fuerza que suprimían la visibilidad del movimiento que los arqueólogos querían estudiar (véase Gnecco y Langebaek, 2006b; Yoffee, I993).

En Colombia estas categorías asociadas con las estructuras de determinadas sociedades fueron adicionadas a los mapas en los que se enseñaba la distribución espacial de las culturas que se habían definido con base en los datos etnohistóricos. Allí mismo cobraron un valor cronológico y se asociaron con ciertos materiales, como el trabajo orfebre y los trabajos arquitectónicos de cierta envergadura. De esta manera se reafirmaban los modelos con los que ya se contaba, adicionándoles un nivel más.

En breve, sobre estos dos tipos de proposiciones -geográficas/históricas y estructurales- se define y justifica el empleo de un eje central que garantiza la legitimidad de un puente que relaciona el entonces y el ahora, permitiendo el desplazamiento en ambas direcciones. El eje de este proceso ha sido la analogía 
etnográfica. Este puente permite, además, incorporar de manera casi automática otros supuestos que se sospecha constituyen una condición previa y permanente de la analogía. Esto último hace problemático el empleo de las analogías etnográficas, dado que en los contextos en los cuales se emplean no se sopesan sus alcances y su importancia (Stahl, 1993; Wylie, I985b). Este es un viejo problema que parece ser más agudo aún en las arqueologías orientadas a la reconstrucción de las historias culturales.

\title{
EPÍlOGO: ¿QUÉ NOS QUEDA?
}

\begin{abstract}
AS CONJETURAS QUE SE PUEDEN DERIVAR DE ESTE ESCRITO SE PUEDEN ORganizar en dos direcciones: por un lado se encuentran aquellas -de carácter general, como las relativas al trabajo antropológico-arqueológico en un contexto amplio. En segundo término están las que tienen que ver con el trabajo de antropólogos y arqueólogos en Colombia. De estas últimas se derivan algunas preguntas sobre las relaciones futuras entre estos dos grupos de especialistas.
\end{abstract}

La forma como se emplean las analogías etnográficas para ilustrar el pasado o justificar la permanencia de ciertos rasgos observados del registro etnográfico revela un hecho que resulta curioso: antropólogos y arqueólogos desconocen los contenidos y los problemas de quienes trabajan en las otras especialidades de la antropología. Evidentemente muchos aspectos de la práctica de la antropología no parecen alcanzar el nivel de integración requerido, problema que se origina desde la formulación de los principios y las definiciones básicas que en teoría dan coherencia al campo de trabajo ${ }^{28}$ y que se refleja en la enseñanza de la

28. Véase Watson (I995), para una discusión sobre el papel del concepto de cultura en estos dos campos: etnología-etnografía y arqueología y los problemas que implica.

\section{disciplina.}

En segundo término, y aún dentro de conjeturas de carácter general, se puede anotar que la manera como antropólogos y arqueólogos han empleado las informaciones y los enfoques generados por sus contrapartes para alimentar el desarrollo de sus investigaciones ha contribuido a la aceptación de algunos supuestos. Estos no han sido examinados en detalle antes de ser adoptados en el contexto del nuevo campo. Por esta vía múltiples conceptos cruzan las fronteras del saber, 
nociones que no pasaron por el riguroso examen que se requiere para tener validez y ser de utilidad en el nuevo contexto. Con el tiempo regresarán al campo en el cual se originaron, cargadas de nuevos supuestos.

Los antropólogos contemporáneos, a pesar de encontrarse más preocupados por la historia que aquellos de hace diez años, en cierto sentido aún siguen moviéndose en un espacio sincrónico. Esto es particularmente cierto para quienes trabajan en la amazonia. Considerar unos pocos años en el pasado, empleando parámetros definidos a partir de modelos presentes, no es una forma segura de remontarse en el tiempo. O bien estos antropólogos corren el riesgo de asumir que el pasado es semejante al presente, o resulta necesario aceptar que existen constantes -rasgos atemporales-cuya identificación permite edificar "otros tiempos”. Esto último, por supuesto, compromete la idea de cambio cultural que se maneja, dado que implica la existencia de un ancla, un fuerte lastre, que evita que veamos otras alternativas. Posiblemente por ello la historia de la que hablan los antropólogos es una historia que desde el punto de vista de la que estudian los arqueólogos resulta bastante etnocéntrica y difícil de leer.

Antropólogos y arqueólogos se distancian en la idea que unos y otros tienen de aquello que denominan pasado. Ahora que los antropólogos retoman una vez más la idea de historia, y que algunos arqueólogos se ocupan de su relación con otras áreas como la historia y la etnología, es necesario repensar las continuidades y discontinuidades que hemos identificado en el tiempo. Si la antropología está interesada en desarrollar una teoría social que dé cuenta de procesos de largo plazo necesita de la arqueología para lograrlo. Igualmente los arqueólogos necesitan de la etnografía para generar una teoría de las sociedades y sus transformaciones, partiendo del estudio del registro de los restos dejados por ellas.

El empleo de las analogías etnográficas en Colombia hace evidente algunos puntos. El trabajo de los etnógrafos y el realizado por los arqueólogos en Colombia parece pertenecer a esferas diferentes. Coinciden en la construcción de una representación que gira en torno de y promueve un pensamiento sobre la diversidad cultural, al tiempo que unifica el territorio nacional del pasado y el presente. Esta presentación tiene un lugar destacado en los textos de divulgación, así como en la representación que se hace en el museo. A pesar de ello parece existir un divorcio entre los 
oficios de antropólogos y arqueólogos. No existe un programa de investigación que aproxime a unos y otros, tampoco una teoría que los dirija hacia puntos semejantes.

En el caso colombiano el pasado se simplificó, inicialmente mediante el uso de las crónicas y luego de la mano del dato etnográfico. Esta fue la base que dio origen a la representación del museo: imagen para ser consumida por un gran público, al cual se le escapan los complejos malabares realizados tras bambalinas para normalizar el pasado. Este tratamiento del pasado impuso un límite para las interpretaciones, al circunscribir el conocimiento arqueológico a la visualización que desde y para el presente realizan los antropólogos. Es evidente que en esta relación el conocimiento arqueológico queda en una posición de subordinación respecto a los datos etnológicos y etnográficos que emplea. Así se reducen las posibles alternativas para la reconstrucción del pasado.

Los arqueólogos colombianos no han estado dispuestos a discutir seriamente el papel de la historia y la historia que los vincula a la antropología. Claro, esta discusión no sería necesaria si el propósito de la arqueología colombiana es describir sucesos históricos individuales, como lo ha hecho con el desarrollo de las historias culturales. Tal vez por esta falta de reflexión en los programas de antropología del país se sigue conservando el viejo esquema de los cuatro campos, y el museo sigue presentando el sueño que alguien tuvo alguna vez sobre el pasado, olvidando las necesidades de los usuarios y sus historias.

Si la arqueología y la antropología en Colombia tienen un objeto de estudio en común deben ser capaces de contribuir a la formación de un marco de referencia que les permita interactuar de una manera más estrecha. Se esperaría que la arqueología derivara de la antropología un corpus conceptual y que contribuyera al mismo; sin embargo, la arqueología en Colombia ha sido pasiva respecto de las discusiones que los antropólogos tienen. Estos últimos, por su parte, parecen ignorar a los arqueólogos y sus trabajos. De forma particular la corriente posmoderna, tan de moda en algunos sectores, se dibuja como un torbellino arrasador que con su crítica derriba viejos mitos. Lástima, su capacidad constructiva está mermada por la falta de un diálogo que edifique e incorpore. Si el propósito de la arqueología colombiana es el entendimiento de lo que ocurrió en el pasado, 
sería necesario entonces discutir el valor de la antropología en esta labor. Obviamente la antropología es solo una de las ciencias sociales que le puede proporcionar un punto de referencia que fortalezca la práctica arqueológica. La historia, la sociología, las ciencias políticas y la geografía son, entre otras, fuentes que pueden contribuir inmensamente al trabajo de los arqueólogos. Cabe preguntarse hasta dónde la arqueología colombiana es antropología colombiana.

\section{ReFERENCIAS}

Ascher, R. "Analogy in archaeological interpretation". Southwestern Journal of Anthropology, I7 (I96I): 317-325.

Augé, Marc. Oblivion. Minneapolis: University of Minnesota Press, 2004.

- Los “no lugares”. Espacios del anonimato. Una antropología de la sobremodernidad. Barcelona: Gedisa, I996.

BalÉE, William L. “The research program of historical ecology”. Annual Review of Anthropology, 35 (2006): 75-98.

Binford, Lewis R. Nunamiut ethnoarchaeology. Nueva York: Academic Press. I978.

- "Archaeology as anthropology". American Antiquity, 28 (I962): 2I7-225.

Bingham, Paul. "Human evolution and human history: A complete theory”. Evolutionary Anthropology, 9 (6) (2000): 248-257.

BoAs, Franz. "The methods of ethnology”. En Anthropological theory. An introductory history, editado por R. Jon McGee y Richard L. Warms. Mayfield Pubishing Company, I996.

Butzer, Karl. Archaeology as human ecology. Method and theory for a contextual approach. Cambridge University Press, I982.

CARneIro, Robert. Evolutionism in cultural anthropology. A critical history. Boulder, Co.: Westview, 2003.

"What happened at the flashpoint? Conjectures on chiefdom formation at the very moment of conception". En Chiefdoms and Chieftaincy in the Americas, editado por Elsa M. Redmond. Gainsville: University of Florida Press, I998.

"Chiefdom-level warfare as exemplifield in Fiji and the Cauca Valley”. En The anthropology of war, editado por J. Haas. Wilshire: Cambridge University Press, I990. 
Chagnon, Napoleón. Yanomamo, the fierce people. Nueva York: Holt, Rinehart and Winston, I968.

Соок Noble, DAvID. Born to die. Disease and the New World conquest, I492-1650. New approaches to the Americas. Cambridge University Press, I998.

Correa, FrançoIs. "Interpretaciones antropológicas sobre lo "indígena” en Colombia”. Universitas Humanística, 62 (2006): I5-4I.

- El sol del poder. Simbología y política entre los muiscas del norte de los Andes. Bogotá: Universidad Nacional de Colombia, 2004.

"La reciprocidad como modelo cultural de la reproducción del medio y la sociedad taiwano”. En La selva humanizada: ecología alternativa en el trópico húmedo colombiano, editado por François Correa. Bogotá: Instituto Colombiano de Antropología-Fondo FEN Colombia-Fondo Editorial Cerec, I990.

Descola, Philippe. La selva culta. Simbolismo y praxis en la ecología de los achuar. Quito: Instituto Francés de Estudios Andinos-Ediciones Abya Yala, I987.

Flórez, Franz, Santiago Mora y María Isabel Patiño. "De la edad de piedra... a la edad de la inocencia”. En Nuevas memorias sobre las antigüedades neogranadinas o de la cronología en la arqueología colombiana y otros asuntos, editado por Santiago Mora y Franz Flórez. Bogotá: Colciencias, I997.

Ford, James A. "On the concept of types". American Anthropologist, 56 (I) (I954a): 42-54.

- "Comment on A. C. Spaulding, "Statistical techniques for the discovery of artifact types””. American Antiquity, I9 (4) (I954b): 390-39I.

FRANKY, CARLOS EDUARDO. "El poblamiento del noroeste amazónico visto desde los tanimuca (tucano oriental). Una aproximación desde tradiciones orales indígenas de la amazonia colombiana”. En Pueblos y paisajes antiguos de la selva amazónica, editado por Gaspar Morcote, Santiago Mora y Carlos Franky. Bogotá: Universidad Nacional de Colombia, Tearaxacum, 2006.

Fried, Morton H. The evolution of political society. Nueva York: Random House, 1967.

GneCCO, Cristóbal. "La indigenización de las arqueologías nacionales”. Convergencias, 27 (2002): I33-I49.

Multivocalidad histórica: hacia una cartografía postcolonial de la arqueología. Bogotá: Departamento de antropología, Universidad de los Andes, I999a.

"Archaeology and historical multivocality: A reflection from the colombian multicultural context". En Archaeology in Latin 
America, editado por G. C. Politis y B. Alberti. Londres: Routledge, I999b.

Gnecco Cristóbal y Carl Henrik Langebaek (editores). Contra la tiranía tipológica en arqueología: una visión desde Suramérica. Bogotá: Ediciones Uniandes-Ceso, 2006a.

. "Contra la tiranía del pensamiento tipológico (Introducción)”. En Contra la tiranía tipológica en arqueología: una visión desde Suramérica, editado por C. Gnecco y C. Langebaek. Bogotá: Ediciones Uniandes-Ceso, 2006b.

Goldman, Irving. Ancient Polynesian society. Chicago y Londres: The University of Chicago Press, I970.

Gómez López, Augusto. "Fragmentos para una historia de los siona y de los tukano occidentales". InVersa. Revista de Estudiantes de Arqueología, 2 (2006): 80-I07.

"Putumayo: indios, misión, colonos y conflictos I845-1970. Fragmentos para una historia de los procesos de incorporación de la frontera amazónica y su impacto sobre las sociedades indígenas”. Tesis doctoral, Universidad Nacional de Colombia. Bogotá, 2005.

Goulard, JeAn Pierre. “De una a otra arqueología”. En Pueblos y paisajes antiguos de la selva amazónica, editado por Gaspar Morcote, Santiago Mora y Carlos Franky. Bogotá: Universidad Nacional de Colombia, Taraxacum, 2006.

Gould, Richard A. y J. E. Yellen. "Misreading the past: A reply to Binford concerning hunter-gatherer site structure”. Journal of Anthropological Archaeology, IO (I99I): 283-298.

Gould, Richard A. y Patty J. Watson. "A dialogue on the meaning and use of analogy in ethnoarchaeological reasoning". Journal of Anthropological Archaeology, I (I982): 355-38I.

Gow, Peter. An Amazonian myth and its history. Oxford University Press, 200I.

Heckenberger, Michael J. The ecology of power. Culture, place, and personhood in the Southern Amazon, A.D. Iooo-2000. Nueva York y Londres: Routledge, 2005.

"Rethinking the Arawakan diaspora: Hierarchy, regionality, and the Amazonian formative". En Comparative Arawakan histories. Rethinking language family and culture area in Amazonia, editado por Jonathan D. Hill y Fernando Santos-Granero. Urban y Chicago: University of Illinois Press, 2002.

Hodder, Ian. The archaeological process. An introduction. Oxford: Blackwell Publishers, I999. 
I986.

Hugh Jones, Steve. “Historia del Vaupés”. Maguaré, I (I98I): 29-5I.

JoNES, ANDREw. "From the perception of archaeology to the anthropology of perception. An interview with Tim Ingold". Journal of Social Archaeology, 3 (I) (2003): 5-22.

Kelekna, Pita. "War and theocracy". En Chiefdoms and Chieftaincy in the Americas, editado por Elsa M. Redmond. Gainsville: University of Florida Press, I998.

Langebaek, Carl Henrik. "Dossier: historia y ciencias sociales. Historia y arqueología: encuentros y desencuentros”. Historia Crítica, 27 (2004), enero-junio. http://historiacritica.uniandes.edu.co/html/27/ art_langebaek.htm

Arqueología colombiana. Ciencia, pasado y exclusión. Bogotá: Colciencias. Colección Colombiana Ciencia y Tecnología, 2003.

“¿Quién vive aquí? Vivienda y cambio social en Colombia prehispánica: un ensayo preliminar”. En Nuevas memorias sobre las antigüedades neogranadinas o de la cronología en la arqueología colombiana y otros asuntos, editado por Santiago Mora y Franz Flórez. Bogotá: Colciencias, I997.

Langebaek, Carl, Emilio Piazzini, Alejandro Dever e Iván Espinosa. Arqueología y guerra en el valle de Aburrá: estudio de cambios sociales en una región del noroccidente de Colombia. Bogotá: Uniandes, 2002.

LATHRAP, D. W. The Upper Amazon. Londres: Thames and Hudson, I970.

LÉvi-Strauss, Claude. The view from afar. Nueva York: Basic Books, I985.

Llanos VARgas, HÉctor. "Los quimbayas y sus vecinos: problemas arqueológicos para los museos regionales de Armenia, Pereira y Manizales”. Boletín del Museo del Oro, I7 (I986): 78-83.

LYMAN, LEE R. "Archaeology's quest for a seat at the high table of anthropology”. Journal of Anthropological Archaeology, 26 (2007): I33-I49.

Matapí, Carlos y Uldarico Matapí. Historia de los Upichia. Bogotá: TropenBos Colombia, I997.

Meggers, Betty. "Environment and culture in the Amazon basin: An appraisal of the theory of environmental determinism". Studies in human ecology. Social science Monographs, 3 (I957): 7I-89.

Molinié, Antoinette. "The resurrection of the Inca: The role of Indian representations in the invention of the Peruvian nation”. History $\mathcal{E}$ Anthropology, I5 (3) (2004): 233-250. 
Mora, Santiago. Amazonia, pasado y presente de un territorio remoto. Bogotá: Universidad de los Andes-Fondo de Promoción a la Cultura, 2006.

Nicholas, David. Ethnoarchaeology in action. Nueva York: Cambridge University Press, $200 I$.

Nimuendajú, Curt. "Reconocimiento dos rios Içana, Ayarí e Uaupés". Journal de la Societé des Americanistes, 39 (I950).

ObeyeseKere, Gananth. "British cannibals: Contemplation of an event in the death and resurrection of James Cook, explorer". Critical Inquiry, I8 (1992a): 630-654.

The apotheosis of Capitan Cook: European mythmaking in the Pacific. Princeton: Princeton University Press, I992b.

O’Brien Michael J. y R. Lee Lyman. “The epistemological nature of archaeological units". Anthropological Theory, 2 (2002): 37-56.

Orme, Bryony. "Twentieth-century prehistorians and the idea of ethnographic parallels". Man, 9 (2) (I974): I99-2I2.

OsBorn, Ann. El vuelo de las tijeretas. Bogotá: Fundación de Investigaciones Arqueológicas Nacionales, Banco de la República, I985.

Palacio Germán y Astrid Ulloa (editores). Repensando la naturaleza. Encuentros y desencuentros disciplinarios en torno a lo ambiental. Bogotá: Universidad Nacional de Colombia, sede Leticia-ImaniICAHN-Colciencias, 2002.

Patterson, Thomas C. "Social archaeology in Latin America: An appreciation”. American Antiquity, 59 (1994): 53I-537.

Peregrine, Peter. "Cross-cultural approaches in archaeology: Comparative ethnology, comparative archaeology, and archaeoethnology". Journal of Archaeological Research, I2 (3) (2004): 28I-309.

. "Cross-cultural comparative approaches in archaeology". Annual Review of Anthropology, 30 (200I): I-I8.

PinedA, Roberto. "La historia, los antropólogos y la amazonia”. Antípoda. Revista de Antropología y Arqueología, I (2005): I22-I35.

Intérpretes de milenios de diversidad. Exposición permanente de arqueología. Milenios de diversidad. Catálogo-Guía. Bogotá: Museo Nacional de Colombia- Instituto Colombiano de Antropología, I994.

Programa de Voluntariado Universitario. "Conversación con Ernestina Mamaní. Proyecto de promoción de patrimonio cultural e histórico en sociedades puneñas: el rol de los museos locales”. Arqueología Suramericana, 3 (I) (2007): 20-28.

Ramenosfsky, Ann, Alicia K. Wilbur y Anne C. Stone. "Native American disease history: Past, present and future directions". World Archaeology, 35 (2) (2003): 24I-257. 
RAPPAPORT, JOANNE. La política de la memoria. Interpretación indígena de la historia de los Andes colombianos. Popayán: Universidad del Cauca, 2000.

"The path of the three staffs of office: History and territorial organization in a northern Andean community 1537-I987”. Ponencia presentada en el seminario American Colonial History. Davidson, North Carolina, I988a.

"La organización socio-territorial de los pastos: una hipótesis de trabajo”. Revista de Antropología Universidad de los Andes, 4 (2) (I988b): 67-IO4.

REDMOND, ElsA. "In war and peace. Alternative paths to centralized leadership". En Chiefdoms and Chieftaincy in the Americas, editado por Elsa M. Redmond. Gainsville: University of Florida Press, 1998.

REICHEL, ELIZABETH. "La danta y el delfín: manejo ambiental e intercambio entre dueños de maloca y chamanes. El caso Yukuna-Matapi (Amazonas)”. Revista de Antropología, I-2 (I989): 68-I33.

__ "Asentamientos prehispánicos en la amazonia colombiana”. En Colombia Amazónica. Bogotá: Universidad Nacional de ColombiaFEN Colombia, 1987.

Reichel-Dolmatof, Gerardo. Rainforest shamans. Essays on the Tukano Indians of the Northwest Amazon. Londres: Themos Books, I997.

- The forest within. The world-view of the Tukano Amazonian Indians. Londres: Themis Books-Green Books-Fozhole-DartingtonCoama Programme-Gaia Foundation, I996.

- Orfebrería y chamanismo. Un estudio iconográfico del Museo del Oro. Medellín: Compañía Litográfica Nacional, I988.

- Cosmología como análisis ecológico: una perspectiva desde la selva pluvial. Estudios antropológicos. Bogotá: Instituto Colombiano de Cultura, I977.

Colombia. Ancient peoples and places. Nueva York: Frederick A. Prager, Publishers, 1965.

Restrepo, Ernesto. "Las invasiones Caribes”. Boletín de Historia y Antigüedades, I (5) (1903): I96-2II.

Rodríguez, Dalvard DominiQue. "Renovación del Museo. Nuevos discursos, nuevas preguntas, nuevas necesidades pedagógicas, nuevos servicios", s. f. http://www.banrep.gov.co/museo/esp/nm_discursos. htm\#up

Rival, LaURA. Trekking through history. The Huaorani of amazonian Ecuador. Nueva York: Columbia University Press, 2002.

Roscoe, Paul B. "New Guinea leadership as ethnographic analogy: A critical review”. Journal of Archaeological Method and Theory, 7 (2) (2000): 79-I26. 
Roosevelt, Anna. "Chiefdoms in the Amazon and Orinoco". En Chiefdoms in the Americas, editado por Robert Drennan y Carlos Uribe. Lanham: University Press of America, I987.

Rouse, Irving. "The classification of artifacts in archaeology". American Antiquity, 25 (3) (1960): 313-323.

RuIZ, Jorge ARMANDO. "El patrimonio arqueológico local y la participación comunitaria en Obando-San Agustín-Huila”. Ponencia presentada al I Congreso de arqueología en Colombia. Sociedad Colombiana de Arqueología-Universidad de Caldas. Manizales, 28 al 30 de octubre de I999, I999.

Sahlins, Marshall. How "natives" think about Capitan Cook, for example. Chicago y Londres: The University of Chicago Press, I995.

- "Poor-man, big-man, rich man, chief: Political types in Melanesia and Polynesia”. Comparative Studies in Society and History, 5 (3) (1964): 285-303. Reimpresión en Conformity \& conflict. Readings in cultural anthropology, editado por J. P. Spradley y D. W. McCurdy. Nueva York: Harper Collins Publisher, I990.

" "Other times, other customs: The anthropology of history". American Anthropologist, 85 (3) (I983): 517-544.

SAntos-Granero, Fernando. "Writing history into the landscape: Space, myth, and ritual in contemporary Amazonia”. American Ethnologist, 25 (2) (I998): I28-I48.

SCHLENKER, JuANA. "Arqueología e identidad entre indígenas y colonos en el alto Caquetá”. En Arqueología al desnudo. Reflexiones sobre la práctica disciplinaria, editado por Cristóbal Gnecco y Emilio Piazzini. Popayán: Editorial Universidad del Cauca. Serie Estudios Sociales, 2003.

SERVICE, Elman. Origins of the state and civilization: The process of cultural evolution. Nueva York: Norton, I975.

Primitive social organization: An evolutionary perspective. Nueva York: Random House, I97I.

Spaulding, Albert C. "Reply to Ford". American Antiquity, in (4) (1954): 39I-393.

"Statistical techniques for the discovery of artifact types". American Antiquity, I8 (I953): 305-313.

STAHL, ANN BROKER. "Concepts of time and approaches to analogical reasoning in historical perspective”. American Antiquity, 58 (2) (I993): 235-260.

Steward, Julian. "Cultural evolution". En Evolution and ecology. Essays on social transformation, editado por Jane C. Steward y Robert F. Murphy. Urbana: University of Illinois Press, I977. 
Stiles, Daniel. "Ethnoarchaeology: A discussion of methods and applications”. Man, I2 (I) (I977): 87-IO3.

Sturtevant, William C. "Anthropology, history, and ethnohistory". Ethnohistory, I3 (I966): I-5I.

TRIGGER, BRUCE. A history of archaeological thought. Cambridge y Nueva York: Cambridge University Press, 1989.

"Ethnoarchaeology: Some cautionary considerations". En Ethnography by archaeologist, editado por Elizabeth Tooker. 1978 Preceedings of the American Ethnological Society. The American Ethnological Society, I982a.

\section{(I) (I982b): I-I9.}

Trimborn, Hermann. Señorío y barbarie en el Valle del Cauca. Biblioteca del Gran Cauca. Popayán: Editorial Universidad del Cauca, 2005 (I949).

Uribe, María Victoria y Fabricio Cabrera. "Estructuras de pensamiento en el altiplano nariñense: evidencias de la arqueología”. Revista de Antropología Universidad de los Andes, 4 (2) (I988): 36-65.

VAsco, Luis Guillermo. Nacionalidades indígenas y estado en Colombia. Entre selva y páramo. Bogotá: Instituto Colombiano de Antropología e Historia, 2002.

"Arqueología e identidad: el caso guambiano". En América Latina hoy, editado por Gustavo Politis. Bogotá: Fondo de Promoción de la Cultura, I992.

VAydA, Andrew P. "Expansion and warfare among Swidden agriculturalists”. En Environment \& cultural behavior. Ecological studies in cultural anthropology, editado por Andrew P. Vayda. Austin y Londres: Texas Press Sourcebooks in Anthropology, I969.

VIDAL, SILVIA. “The Arawak-speaking groups of Northwestern Amazonia: Amerindian cartography as a way of preserving and interpreting the past”. En Histories and historicities in Amazonia, editado por Neil L. Whitehead. Lincoln y Londres: University of Nebraska Press, 2003.

Watson, Patty Jo. "Archaeology, anthropology, and culture concept". American Anthropologist, 97 (4) (I995): 682-694.

White, Leslie A. "Forward". En Evolution and culture, editado por Thomas G. Harding, David Kaplan, Marshall D. Sahlins y Elman R. Service. Ann Arbor: The University of Michigan Press, Ig68 (I960). The science of culture: A study of man and civilization. Nueva York: Grove Press, I949. 
- "Evolutionism in cultural anthropology: A rejoinder". American Anthropologist, 49 (3) (I947): 400-4I3.

- "Energy and the evolution of culture". American Anthropologist, 43 (3) (I943): 335-356.

WhiteHeAd, NeIL. "The crises and transformations of invaded societies: The Caribbean (1492-1580)". En The Cambridge history of the natives peoples of the Americas. Vol. III. South America. Part I. Cambridge University Press, I999.

Willey, Gordon y Philip Phillips. Method and theory in American archaeology. Chicago: University of Chicago Press. I958.

WOLF, ERIC. Envisioning power: Ideologies of dominance and crisis. Berkeley: University of California Press, I999.

Europe and the people without history. Berkeley: University of California Press, I982. Press, I959.

Wylie, Alison. "Between philosophy and archaeology". American Antiquity, 50 (2) (1985a): 478-490.

" "The reaction against analogy". Advances in archaeological method and theory, 8 (I985b): 63-III.

Yoffee, Norman. "Too many chiefs? (or, safe texts for the 9os)". En Archaeological theory: Who sets the agenda?, editado por Norman Yoffee y Andrew Sherratt. Cambridge: Cambridge University Press, I993.

Zucchi, Alberta. "Ríos de aguas blancas y negras, asentamientos, organización social y patrones migratorios de grupos Arawacos del alto Negro venezolano". En Pueblos y paisajes antiguos de la selva amazónica, editado por Gaspar Morcote, Santiago Mora y Carlos Franky. Bogotá: Universidad Nacional de Colombia, Tearaxacum, 2006.

"A new model of the Arawakan expansion". En Comparative Arawakan Histories. Rethinking language family and culture area in Amazonia, editado por Jonathan D. Hill y Fernando Santos-Granero. Urbana y Chicago: University of Ilinois Press, 2002. 